\title{
Relationship between anthropometric and strength variables and maximal throwing velocity in female junior handball players - a pilot study
}

\author{
Javad Sarvestan*, Václav Riedel, Zuzana Gonosová, Petr Linduška, and Miroslava Přidalová \\ Faculty of Physical Culture, Palacký University Olomouc, Olomouc, Czech Republic
}

Copyright: (c) 2019 J. Sarvestan et al. This is an open access article licensed under the Creative Commons Attribution License (https://creativecommons.org/licenses/by/4.0/).

\begin{abstract}
Background: Throwing velocity is one of the determinant scoring elements in handball. However, our knowledge of anthropometric factors and shoulder muscle strength among female players and how these affect throwing velocity is limited. Objective: This study aimed to assess the relationships between throwing velocity and the physical traits of anthropometric factors and shoulder muscle strength in female handball players. Methods: Nine elite female junior handball players (age 17.1 \pm 1.7 years, body height $169.7 \pm 3.8 \mathrm{~cm}$, body mass $66.2 \pm 6.8 \mathrm{~kg}$, experience with handball $8.9 \pm 1.7$ years) participated in the study. Spearman's correlation coefficient was used to detect correlations between throwing velocity and shoulder internal rotator torque, explosive strength deficit, and anthropometric parameters of the upper limb. Results: Our results showed significant correlations between throwing velocity and upper limb length $(r=.82)$ and hand length $(r=.68)$; however, no significant correlations were observed between throwing velocity and shoulder internal rotator peak torque, explosive strength deficit, lean body mass of upper limb, and other anthropometric parameters. Conclusions: The results of this study suggest that the lengths of the upper limb and hand are the two main elements that affect throwing velocity in female handball players; this could be employed in talent identification.
\end{abstract}

Keywords: shoulder internal rotators, explosive strength deficit, upper limb strength, handball throw, power

\section{Introduction}

Over-arm throwing ability is an essential element of success in various sports associated with frequent overhead actions. Throwing velocity also affects athletic efficiency in handball, volleyball, and baseball (Andrade, de Carvalho Koffes, Benedito-Silva, da Silva, \& de Lira, 2016). From the corporeal perspective, handball is an intermittent and contact sport that involves highintensity endeavours in the shortest possible time, such as running, jumping, and throwing the ball, followed by low-intensity or rest moments. Hence, given the significance and frequency of over-arm movements in handball training and competitions, the shoulder complex experiences severe mechanical stresses. Furthermore, handball involves reiterative bouts of high-velocity arm throwing, which demands dynamic stabilization

\footnotetext{
* Address for correspondence: Javad Sarvestan, Department of Natural Sciences in Kinanthropology, Faculty of Physical Culture, Palacký University Olomouc, třída Míru 117, 77111 Olomouc, Czech Republic. E-mail: javad.sarvestan@upol.cz
}

to maintain the integrity of the glenohumeral joint (Andrade et al., 2013; Mascarin et al., 2017).

The glenohumeral joint is a ball-and-socket joint with three degrees of freedom; these features give the joint an unstable axis of rotation because the joint has a small cross-sectional area (Andrade, Fleury, de Lira, Dubas, \& da Silva, 2010). Coordinated action from the shoulder muscle complex is vital to efficient performance and reducing the risk of injury (Andrade et al., 2010; Yildiz et al., 2006). Previous studies divided handball throwing into three motions: cocking, acceleration, and followthrough (Wagner, Buchecker, von Duvillard, \& Müller, 2010; Wagner, Pfusterschmied, von Duvillard, \& Müller, 2011). Concerning the cocking phase, the shoulder internal rotators (IR) benefit from a stretch-shortening cycle in an eccentric motion followed by concentric muscle contraction, which directly affects the throwing velocity in the acceleration phase. In the follow-through phase, the role of external rotators becomes more crucial; these muscles must provide the shoulder joint with sufficient protection to prevent injury.

Many studies have employed various methods for quantifying upper limb muscle quality to investigate 
the effects of shoulder muscle strength and power on throwing techniques and shoulder injury prevention (Andrade et al., 2016, 2010; Granados, Izquierdo, Ibanez, Bonnabau, \& Gorostiaga, 2007; Pontaga \& Zidens, 2014). Elite handball players are trained to produce higher measures of shoulder peak torque compared to non-elite players (Wagner, Fuchs, \& von Duvillard, 2018), which could positively influence throwing velocity according to the angular-linear velocity relationship (Halliday, Resnick, \& Walker, 2013). Shoulder muscle characteristics were formerly studied at various velocities including $60 \% \mathrm{~s}, 90 \%$, $240 \%$, and $300 \%$ s (Andrade et al., 2016; Fleck et al., 1992; Pontaga \& Zidens, 2014). Shoulder rotator cuff strength training is already reported to confer enhancement on internal rotation (IR) performance by increasing in IR power output and throwing velocity in both standing and jumping throws (Mascarin et al., 2017; Raeder, Fernandez-Fernandez, \& Ferrauti, 2015). Poor muscle strength, on the other hand, was shown to increase the probability of early fatigue and decrease the torque of both internal and external rotators (Andrade et al., 2016).

In sports movements that require high-power output such as a handball throw, the time to reach maximum force is very short. Explosive strength deficit (ESD) is used to describe the relationship of maximal force generated under ideal circumstances and the force generated under more relevant task-specific conditions (Weiss, Fry, \& Relyea, 2002; Zatsiorsky \& Kraemer, 2006). In other words, ESD depicts the percentage of individual strength potential that was not utilized in a given task (Zatsiorsky \& Kraemer, 2006). Therefore, measures of ESD are expressed as the difference between performance and the expected ideal, so ESD values are inversely proportional to performance, whereas other performance characteristics are typically directly proportional to power output (Weiss et al., 2002). In sports that involve motions that begin with a stretch-shortening cycle and are performed with high velocity, ESD is expected to be relatively low (Weiss et al., 2002).

Segment length and muscular body shape are two essential advantages in handball (Bon, Pori, \& Šibila, 2015; Chaouachi et al., 2009; Hasan, Rahaman, Cable, \& Reilly, 2007; Milanese, Piscitelli, Lampis, \& Zancanaro, 2011). The most successful handball teams are generally taller and possess less body fat, whether male or female (Bon et al., 2015; Hasan et al., 2007). Additionally, young handball players are reported to be taller with more body mass compared to peers who play different sports (Bon et al., 2015). Theoretically, longer segmental length could significantly increase the linear velocity of the projectile at the throwing moment; however, segmental length could also decrease throwing velocity by an excessive moment of inertia (Halliday et al., 2013). No significant correlation was seen between anthropometric parameters and throwing velocity in handball players (Chaouachi et al., 2009). However, it has been reported that a combination of general anthropometric parameters, such as body mass, height, and body mass index and handball-specific anthropometric parameters, including hand perimeter, ring finger length, middle finger length, and arm span are significantly correlated with throwing velocity (Debanne \& Laffaye, 2011). Concerning strength measures of upper limbs, higher wrist grip value is also reported to have a notable impact on throwing velocity (Vila et al., 2012).

Powerful, precise throwing is an excellent approach to scoring goals in handball, particularly when there is an eight-meter distance to the goal (Wagner et al., 2010). Therefore, based on findings of related studies discussed above, the principal objective of this study was to assess the relationship between throwing velocity and the physical traits of anthropometric characteristics and shoulder muscle strength in female handball players.

\section{Methods}

\section{Participants}

Nine elite female junior handball players (age $17.1 \pm 1.7$ years, body height $169.7 \pm 3.8 \mathrm{~cm}$, body mass $66.2 \pm 6.8 \mathrm{~kg}$, experience with handball $8.9 \pm 1.7$ years) participated in the study. The participants reported no instances of neuromuscular or musculoskeletal injury of the upper extremities in the previous two years. Written statements of informed consent were provided by all participants or their legal representatives (i.e., when participants were less than 18 years old), and the testing protocol was approved by the institutional ethics committee.

\section{Instruments and procedures}

Throwing velocity

To measure throwing velocity, radar (Speed Trac, Gamma, Pittsburgh, PA, USA) was used. Before the measurement, the subjects performed a 15-minute warm-up. The throwing test was conducted as previously described in studies that focused on throwing velocity in handball (van den Tillaar \& Cabri, 2012; van den Tillaar \& Ettema, 2011). Throwing was performed from standing with one limb in front of the body approximately $7 \mathrm{~m}$ in front of the target using a standard ball (size 2, mass $0.360 \mathrm{~kg}$ ). The subjects were asked to throw with maximal strength to the target $(0.5$ $\mathrm{m} \times 0.5 \mathrm{~m}$ ) placed $1.65 \mathrm{~m}$ above the ground. Between 
throws, there was a 1-minute rest. The mean value of throwing velocity was calculated from three successful trials and used for analysis.

\section{Muscle strength}

Muscle strength testing was conducted with an isokinetic dynamometer (IsoMed 2000, D. \& R. Ferstl, Hemau, Germany). The device was calibrated according to the manufacturer's guidelines. The participants performed a non-specific warm-up before the isokinetic measurement. The subject first assumed a testing position that was modified from that used by Ellenbecker and Davies (2000). The subject sat in a custom-made chair with a hip and knee angle at $90^{\circ}$ of flexion; the feet did not touch the ground. The arm was positioned at $70^{\circ}$ of glenohumeral abduction, $10^{\circ}$ horizontal adduction (anterior to the frontal plane), $0^{\circ}$ of rotation (i.e., forearm perpendicular to the ground). The elbow was at $90^{\circ}$ of flexion, as measured by a handheld goniometer. The position of the chair and the height and incline of the dynamometer head and shoulder adapter with the subject's thumb positioned on the medial end of the grip were adjusted to meet the criteria stated above with respect to the axis of the dynamometer and the longitudinal axis of the humerus through the olecranon. To stabilize the body against undesirable movements, Velcro straps were used around the waist and over the shoulders. A total range of motion of $100^{\circ}$ was measured from a starting position at $10^{\circ}$ of external rotation to a final position at $90^{\circ}$ of internal rotation.

Internal rotators were tested at velocities of $30 \%$ and $240 \%$ in concentric mode on the dominant upper limb (i.e., the preferred arm for throwing). Fast acceleration at the beginning and a strong deceleration at the end of the movement defined a throw. Verbal explanation and demonstration, and 3-5 practice trials preceded the test as a part of the specific warm-up and to allow the subject to gain familiarity with the test procedure. After the warm-up, three motions at $30 \%$ and five motions at $240 \% \mathrm{~s}$ were performed in one set with instructions to apply force quickly, forcefully, and throughout the whole range of motion. Rest intervals of 90 seconds were taken between throws. The subjects were not allowed to hold a handle with their contralateral upper limb. The subjects were verbally encouraged by the investigator and visually by realtime feed-back on the monitor. Data were corrected for the effect of gravity.

Data were processed using the manufacturer's software IsoMed Analyze (Version 1.0.5; D. \& R. Ferstl, Hemau, Germany). Results are presented as mean absolute peak torque (PT) and mean relative peak torque (PTR) normalized to body mass at each velocity tested. ESD was calculated as 100 * (PT 30 PT 240)/PT 240, where PT 30 is PT at $30 \%$, and PT 240 is PT at $240 \%$ s (Weiss et al., 2002; Zatsiorsky \& Kraemer, 2006).

\section{Anthropometric variables}

Body height and length parameters were measured with an accuracy of $\pm 0.5 \mathrm{~cm}$ using the anthropometer (A-226, Trystom, Olomouc, Czech Republic); circumferential parameters (arm circumference, flexed arm circumference) with an accuracy of $\pm 0.5 \mathrm{~cm}$ (circumferential measuring tape); width parameters on limbs with an accuracy of $\pm 0.2 \mathrm{~cm}$ using a sliding scale. Body mass was measured with an accuracy of $\pm 0.5 \mathrm{~kg}$, and the analysis of body composition was performed using the multifrequency method of bioelectric impedance with an InBody 720 device (Biospace, Seoul, Korea). The measurements were conducted under standard conditions. The InBody 720 device divides the body into five segments (left and right upper limbs, trunk, and left and right lower limbs) and uses an alternating electrical current with frequencies of $1-1000 \mathrm{kHz}$ to differentiate body mass into total body water (intracellular and extracellular), proteins, minerals, and body fat. Lean body mass on the upper limb $(\mathrm{kg})$ was also determined by the InBody 720 device. The data collected with the InBody 720 were transferred into MS Excel (Version 2013; Microsoft, Redmond, WA, USA) and analysed using the Lookin Body program (Version 3.0; Biospace, Seoul, Korea).

\section{Statistical analysis}

Statistical analyses were performed using Statistica (Version 12; Tulsa, StatSoft, Tulsa, OK, USA). Due to the small sample size, non-parametric statistical procedures were used. To determine the relationships between shoulder IR strength, ESD, lean body mass of the upper limb, and anthropometric characteristics with throwing velocity, Spearman's correlations were used. The significance level was set at $\alpha=.05$.

\section{Results}

No significant correlation was observed between participants' mean IR torque values and throwing velocity either $30 \%$ or $240 \%$ s angular velocity (Table 1 ). ESD measures also showed no significant correlation with mean throwing velocity. Lean body mass of upper limb also had no significant correlation with throwing velocity.

Anthropometrically, a significant correlation was observed between the participants' upper limb length and throwing velocity $(r=.817, p=.007)$. A slightly 
Table 1

Measured variables and correlations with throwing velocity

\begin{tabular}{|c|c|c|c|c|}
\hline \multirow[b]{2}{*}{ Variable } & \multirow[b]{2}{*}{ Mean } & \multirow[b]{2}{*}{$S D$} & \multicolumn{2}{|c|}{ Spearman's correlation } \\
\hline & & & $r$ & $p$ \\
\hline Throwing velocity $(\mathrm{m} / \mathrm{s})$ & 15.7 & 1.4 & - & - \\
\hline PT $240(\mathrm{~N} \cdot \mathrm{m})$ & 15.7 & 2.3 & .183 & .637 \\
\hline PT $30(\mathrm{~N} \cdot \mathrm{m})$ & 21.7 & 3.8 & .383 & .308 \\
\hline PTR $240(\mathrm{~N} \cdot \mathrm{m} / \mathrm{kg})$ & 0.24 & 0.03 & .067 & .865 \\
\hline PTR $30(\mathrm{~N} \cdot \mathrm{m} / \mathrm{kg})$ & 0.33 & 0.08 & .300 & .433 \\
\hline Explosive strength deficit (\%) & 39.3 & 26.4 & .283 & .460 \\
\hline Upper limb lean body mass (kg) & 2.5 & 0.3 & .209 & .589 \\
\hline Upper limb length $(\mathrm{cm})$ & 73.1 & 2.1 & .817 & .007 \\
\hline Upper arm length $(\mathrm{cm})$ & 30.9 & 1.6 & .400 & .286 \\
\hline Forearm length $(\mathrm{cm})$ & 24.2 & 1.0 & -.318 & .404 \\
\hline Hand length (cm) & 18.0 & 2.1 & .683 & .042 \\
\hline Upper arm circumference $(\mathrm{cm})$ & 28.7 & 1.8 & .142 & .715 \\
\hline Flexed upper arm circumference $(\mathrm{cm})$ & 30.0 & 1.6 & .210 & .587 \\
\hline Elbow width $(\mathrm{cm})$ & 6.3 & 0.4 & .310 & .417 \\
\hline Wrist width $(\mathrm{cm})$ & 5.3 & 0.2 & .000 & $>.99$ \\
\hline
\end{tabular}

Note. $\quad$ PT $240=$ absolute peak torque at a velocity of $240 \%$ s; PT $30=$ absolute peak torque at a velocity of $30 \%$ s; PTR $240=$ relative peak torque at a velocity of $240 \%$; PTR $30=$ relative peak torque at a velocity of $30 \%$ s.

weaker, but still significant correlation existed between the hand length and throwing velocity $(r=.683, p=.042)$. Upper arm length and circumferences and forearm length had a weak correlation with throwing velocity.

\section{Discussion}

A handball player's ability to execute a powerful, precise throw while simultaneously gaining position against competitors involves many anthropometric factors and muscle qualities (Vila et al., 2012). The principal objective of this study was to assess the relationship between throwing velocity and the physical traits of anthropometric features and shoulder IR strength of handball players to evaluate the contribution of these factors to throwing performance. Our findings indicate that throwing velocity is significantly correlated with upper limb and hand length of handball players; however, none of the other shoulder IR tests, including lean body mass of upper limb, arm and forearm length, arm and flexed arm circumference, arm and wrist width variables are significantly correlated with throwing velocity.

In terms of upper limb anthropometry, although the participants in this study were elite young female players, anthropometric characteristics of upper limbs were similar to those of elite adult players (Bon et al., 2015; Vila et al., 2012). This can be explained by the physical maturity of the participants in this study. From a physics point of view, an incremental increase in the length of the athlete's hand increases the linear velocity of the projectile according to the angular-linear velocity relationship (Fleisig, Barrentine, Zheng, Escamilla, \& Andrews, 1999; Halliday et al., 2013). Mechanically, this means that an increment of a rotation radius causes a proportional increase in the force applied to the ball, which increases the linear velocity of the ball (Zapartidis et al., 2009). On the other hand, although a longer segment helps increase the linear velocity of a thrown ball, an excessive increase in segmental length might also lead to more inertial momentum (Halliday et al., 2013).

Hand length, a handball-specific anthropometric parameter, has been reported to have a significant correlation with throwing velocity in handball players (Debanne \& Laffaye, 2011; Skoufas, Kotzamanidis, Hatzikotoylas, Bebetsos, \& Patikas, 2003; Zapartidis et al., 2009). The outcomes of this study are in agreement with these previous studies; our results show that hand length has a significant correlation with throwing velocity $(r=.68)$. Increased length is considered important for a stable ball grip and proper throwing technique (Burton, Greer, \& Wiese-Bjornstal, 1993; Zapartidis et al., 2009), and it is generally assumed that a stable ball 
grip gives the athlete the ability to throw a ball with maximal acceleration (Skoufas et al., 2003).

A weak correlation was reported between throwing velocity and upper arm and forearm lengths (Skoufas et al., 2003), and our findings are in agreement with this previous study. Despite thorough analysis, no significant correlation was observed between lean body mass and throwing velocity in the female participants of this study, which is in agreement with a study conducted on elite male players (Chaouachi et al., 2009). Halliday et al. hypothesized that body mass could be beneficial for throwing a handball throw from the perspective of the impulse-momentum relationship (Halliday et al., 2013). Mathematically, a decrease in joint range of motion - shoulder complex in this study - can decrease joint angular displacement; consequently, this leads to reductions in angular and linear velocity at throwing moment. For example, although athletes who play back and pivot positions on a handball team benefit from having a muscular and bulky upper arm. However, throwing velocity was higher in athletes who play in the centre positions, despite having less bulky upper arms (Vila et al., 2012). In this study, only the correlation between the mean of the data collected from all participants was investigated, and game positions, which could lead to different results, were not studied. Based on this fact, an investigation on individual game position might supply more in-depth information about young handball players.

Compared with previous studies, the mean IR torque measured in this study population is similar to the broader population of handball players (Bonetti et al., 2019; Mascarin et al., 2017; Raeder et al., 2015) particularly among female players (Bonetti, 2019). In handball throwing, the motions of triple shoulder horizontal adduction, flexion, and internal rotation occur rapidly in succession when a ball is thrown toward the goal area. Our study showed no significant relationship between upper limb muscle torque and throwing velocity, which agrees with the findings of Fleck et al. (1992). They found no significant correlation between shoulder internal rotation, horizontal adduction, and flexion in set ball shot shots made at a $240 \%$ s velocity (Fleck et al., 1992). Other studies also found no significant correlation between shoulder IR torque and throwing velocity among young male and adult female handball players in shots with ground support (Zapartidis, Gouvali, Bayios, \& Boudolos, 2007).

These findings with could be explained by the fact that when athletes are in contact with the ground, the force transferred through the legs and the trunk may be enough to lower the demand on shoulder joint muscles to develop throwing velocity (Zapartidis et al., 2007). In contrast, with jump shots, athletes cannot benefit from the ground reaction force and have to activate more shoulder muscles to enhance the throwing performance.

Theoretically, ESD has a strong relationship to movements requiring power and rate of force development (Weiss et al., 2002). No study has investigated the ESD correlation with throwing velocity in handball players. Nevertheless, it has been reported that ESD has a negative correlation with performance in the powerful actions that utilize a stretch-shortening cycle, such as countermovement jumps (Weiss et al., 2002). In the arm-cocking phase of a handball throw, a fast lengthening occurs in the shoulder IR before the acceleration phase, which uses the advantage of the stretch-shortening cycle to throw the ball. Given that the players performed isolated shoulder IR torque tests, it was predicted that they would not execute at their true performance level. In addition, the values of ESD measured in this study were close to the measures reported by Weiss et al. in jumping performance (Weiss et al., 2002). More investigations are required to obtain more information regarding powerful actions in handball, such as handball throws.

It is also worth mentioning that the small sample size of this research must be taken into consideration as a limitation of this study.

\section{Conclusions}

The results of this study lead to the following conclusions: the upper limb and hand length are anthropometric parameters that affect throwing velocity in female junior handball players. These findings highlight the significance of upper arm and hand length for elite female handball players and can contribute to the talent identification process for handball coaches and sports scientists. Our results did not show a significant relationship between shoulder IR torque and throwing velocity.

\section{Acknowledgments}

This work was supported by Palacký University Olomouc (grant no. IGA_FTK_2018_006).

\section{Conflict of interest}

There were no conflicts of interest. 


\section{References}

Andrade, M. S., de Carvalho Koffes, F., Benedito-Silva, A. A., da Silva, A. C., \& de Lira, C. A. B. (2016). Effect of fatigue caused by a simulated handball game on ball throwing velocity, shoulder muscle strength and balance ratio: A prospective study. BMC Sports Science, Medicine and Rehabilitation, 8, 13.

Andrade, M. S., Fleury, A. M., de Lira, C. A. B., Dubas, J. P., \& da Silva, A. C. (2010). Profile of isokinetic eccentricto-concentric strength ratios of shoulder rotator muscles in elite female team handball players. Journal of Sports Sciences, 28, 743-749.

Andrade, M. S., Vancini, R. L., de Lira, C. A. B., Mascarin, N. C., Fachina, R. J. F. G., \& da Silva, A. C. (2013). Shoulder isokinetic profile of male handball players of the Brazilian National Team. Brazilian Journal of Physical Therapy, 17, 572-578.

Bon, M., Pori, P., \& Šibila, M. (2015). Position-related differences in selected morphological body characteristics of toplevel female handball players. Collegium Antropologicum, 39, 631-639.

Bonetti, L., Zardo, F., Candiago, B., Finger, A. T., De Marchi, T., \& Tadiello, G. (2019). Isokinetic performance of shoulder external and internal rotators in adolescent female handball athletes. Science \& Sports, 34, e119-e123.

Burton, A. W., Greer, N. L., \& Wiese-Bjornstal, D. M. (1993). Variations in grasping and throwing patterns as a function of ball size. Pediatric Exercise Science, 5, 25-41.

Chaouachi, A., Brughelli, M., Levin, G., Boudhina, N. B. B., Cronin, J., \& Chamari, K. (2009). Anthropometric, physiological and performance characteristics of elite teamhandball players. Journal of Sports Sciences, 27, 151-157.

Debanne, T., \& Laffaye, G. (2011). Predicting the throwing velocity of the ball in handball with anthropometric variables and isotonic tests. Journal of Sports Sciences, 29, 705-713.

Ellenbecker, T. S., \& Davies, G. J. (2000). The application of isokinetics in testing and rehabilitation of the shoulder complex. Journal of Athletic Training, 35, 338-350.

Fleck, S. J., Smith, S. L., Craib, M. W., Denahan, T., Snow, R. E., \& Mitchell, M. L. (1992). Upper extremity isokinetic torque and throwing velocity in team handball. Journal of Strength and Conditioning Research, 6, 120-124.

Fleisig, G. S., Barrentine, S. W., Zheng, N., Escamilla, R. F., \& Andrews, J. R. (1999). Kinematic and kinetic comparison of baseball pitching among various levels of development. Journal of Biomechanics, 32, 1371-1375.

Granados, C., Izquierdo, M., Ibanez, J., Bonnabau, H., \& Gorostiaga, E. (2007). Differences in physical fitness and throwing velocity among elite and amateur female handball players. International Journal of Sports Medicine, 28, 860-867.

Halliday, D., Resnick, R., \& Walker, J. (2013). Fundamentals of physics, extended (10th ed.). Hoboken, NJ: John Wiley \& Sons.

Hasan, A., Rahaman, J., Cable, N., \& Reilly, T. (2007). Anthropometric profile of elite male handball players in Asia. Biology of Sport, 24, 3-12.

Mascarin, N. C., de Lira, C. A. B., Vancini, R. L., de Castro Pochini, A., da Silva, A. C., \& dos Santos Andrade, M. (2017). Strength training using elastic bands: Improvement of muscle power and throwing performance in young

female handball players. Journal of Sport Rehabilitation, 26, 245-252.

Milanese, C., Piscitelli, F., Lampis, C., \& Zancanaro, C. (2011). Anthropometry and body composition of female handball players according to competitive level or the playing position. Journal of Sports Sciences, 29, 1301-1309.

Pontaga, I., \& Zidens, J. (2014). Shoulder rotator muscle dynamometry characteristics: Side asymmetry and correlations with ball-throwing speed in adolescent handball players. Journal of Human Kinetics, 42, 41-50.

Raeder, C., Fernandez-Fernandez, J., \& Ferrauti, A. (2015). Effects of six weeks of medicine ball training on throwing velocity, throwing precision, and isokinetic strength of shoulder rotators in female handball players. Journal of Strength and Conditioning Research, 29, 1904-1914.

Skoufas, D., Kotzamanidis, C., Hatzikotoylas, K., Bebetsos, G., \& Patikas, D. (2003). The relationship between the anthropometric variables and the throwing performance in handball. Journal of Human Movement Studies, 45, 469-484.

van den Tillaar, R., \& Cabri, J. M. (2012). Gender differences in the kinematics and ball velocity of overarm throwing in elite team handball players. Journal of Sports Sciences, 30, 807-813.

van den Tillaar, \& Ettema, G. (2011). A comparison of kinematics between overarm throwing with $20 \%$ underweight, regular, and $20 \%$ overweight balls. Journal of Applied Biomechanics, 27, 252-257.

Vila, H., Manchado, C., Rodriguez, N., Abraldes, J. A., Alcaraz, P. E., \& Ferragut, C. (2012). Anthropometric profile, vertical jump, and throwing velocity in elite female handball players by playing positions. Journal of Strength and Conditioning Research, 26, 2146-2155.

Wagner, H., Buchecker, M., von Duvillard, S. P., \& Müller, E. (2010). Kinematic description of elite vs. low level players in team-handball jump throw. Journal of Sports Science \& Medicine, 9, 15-23.

Wagner, H., Fuchs, P. X., \& von Duvillard, S. P. (2018). Specific physiological and biomechanical performance in elite, sub-elite and in non-elite male team handball players. Journal of Sports Medicine and Physical Fitness, 58, 73-81.

Wagner, H., Pfusterschmied, J., von Duvillard, S. P., \& Müller, E. (2011). Performance and kinematics of various throwing techniques in team-handball. Journal of Sports Science $\&$ Medicine, 10, 73-80.

Weiss, L. W., Fry, A. C., \& Relyea, G. E. (2002). Explosive strength deficit as a predictor of vertical jumping performance. Journal of Strength and Conditioning Research, 16, 83-86.

Yildiz, Y., Aydin, T., Sekir, U., Kiralp, M., Hazneci, B., \& Kalyon, T. (2006). Shoulder terminal range eccentric antagonist/concentric agonist strength ratios in overhead athletes. Scandinavian Journal of Medicine \& Science in Sports, 16, 174-180.

Zapartidis, I., Gouvali, M., Bayios, I., \& Boudolos, K. (2007). Throwing effectiveness and rotational strength of the shoulder in team handball. Journal of Sports Medicine \& Physical Fitness, 47, 169-178.

Zapartidis, I., Skoufas, D., Vareltzis, I., Christodoulidis, T., Toganidis, T., \& Kororos, P. (2009). Factors influencing ball throwing velocity in young female handball players. Open Sports Medicine Journal, 3, 39-43.

Zatsiorsky, V. M., \& Kraemer, W. J. (2006). Science and practice of strength training (2nd ed.). Champaign, IL: Human Kinetics. 